CLINICAL STUDY

\title{
Coronary artery disease risk in Chinese type 2 diabetics: is there a role for paraxonase 1 gene $(\mathrm{Q} 192 \mathrm{R})$ polymorphism?
}

\author{
Douglas Osei-Hyiaman ${ }^{1,2}$, Lifang Hou ${ }^{1}$, Fan Mengbai ${ }^{4}$, Ren Zhiyin ${ }^{3}$, Zhang Zhiming ${ }^{5}$ and Katsumi Kano ${ }^{2}$ \\ ${ }^{1}$ Graduate School of Medicine and ${ }^{2}$ Department of Epidemiology, Institute of Community Medicine, University of Tsukuba, Tsukuba City, Ibaraki-ken, \\ Japan, ${ }^{3}$ Department of Internal Medicine, Taiyuan City Hospital, Shanxi, China, ${ }^{4}$ Department of Emergency Medicine, $2^{\text {nd }}$ Teaching Hospital and \\ ${ }^{5}$ Department of Epidemiology, Shanxi Medical University, Shanxi, China \\ (Correspondence should be addressed to D Osei-Hyiaman, Graduate School of Medicine, University of Tsukuba, Tsukuba City, Ibaraki-ken, \\ Japan 305-8575; Email: shaddai@medscape.com)
}

\begin{abstract}
Objective: Heredity plays an important role in the predisposition to atherosclerotic coronary artery disease (CAD), and its thrombotic complications. Paraoxonase, a high-density lipoprotein-associated enzyme capable of hydrolyzing lipid peroxides, is presumed to contribute to atherosclerosis and CAD. This study investigates the role of human paraoxonase 1 (PON 1) gene (Q192R) polymorphism in CAD risk among Chinese type 2 diabetic cases.

Design: A population-based case-control study of paraoxonase 1 gene (Q192R) polymorphism and the risk of CAD in Chinese type 2 diabetics.

Methods: Subjects included 201 angiographically documented CAD patients with type 2 diabetes and 231 control subjects with type 2 diabetes alone living in central China. Single strand conformational polymorphism (SSCP) analysis was used to screen for PON 1 gene (Q192R) polymorphism.

Results: Frequency of the $R$ allele was $21.5 \%$ in the CAD patients and $12.0 \%$ in the control subjects. The presence of the $R$ allele was significantly associated with risk of CAD (odds ratio $(\mathrm{OR})=1.97$; $95 \%$ confidence interval $(\mathrm{CI})=1.36-2.86)$.

Conclusion: Frequency of the 192R allele of the human paraoxonase 1 gene may be an independent risk factor for $\mathrm{CAD}$ in the Chinese type 2 diabetics studied.
\end{abstract}

European Journal of Endocrinology 144 639-644

\section{Introduction}

Familial clustering of early-onset coronary artery disease (CAD) is well established (1). Type 2 diabetes is a major risk factor for the development of $\mathrm{CAD}$ and subsequent myocardial infarction (MI) (2). Both genetically mediated lipid abnormalities, and environmental factors contribute to the pathogenesis of premature $\mathrm{CAD}$ (3). Although the levels of lipoproteins such as low- and high-density lipoprotein (LDL and HDL) cholesterol may not be abnormal in patients with type 2 diabetes, lipoprotein glycation may be responsible for this abnormal function (4). Genetic markers involved in lipoprotein metabolism and modification may therefore be especially important in the development of CAD and MI in patients with type 2 diabetes. One gene that has been known to play a role in the pathogenesis of $\mathrm{CAD}$ is the human paraoxonase 1 gene located on chromosome 7 (7q21-22) (5).

Paraoxonase (PON) is an HDL-bound enzyme which catalyzes the hydrolysis of organic phosphates and lipid peroxides thereby leading to protection against LDL oxidation, and its subsequent positive role in the risk of
CAD. Paraoxonase is codominantly expressed as $\mathrm{Gln}(Q)$ and $\operatorname{Arg}(R)$ alleles. A strong association between PON 192 polymorphism and PON activity has been established - an indication that this polymorphism could be responsible for the two human serum PON phenotypes, PON A and PON B determined by the $Q$ and the $R$ alleles respectively $(6,7)$. The PON A phenotype is known to be associated with decreased levels of apolipoprotein-B (Apo-B) and triglycerides in the serum (8). Furthermore, it has been reported that the $Q$ allele is associated with decreased serum levels of total cholesterol, triglycerides and Apo-B, and increased serum levels of HDL cholesterol (9). It should, however, be clarified that the effects of paraoxonase on lipoprotein levels in open populations are small, and that the populations used in this study are genetically isolated populations. In other words, lipoproteins do not necessarily confound the relationship between CAD and paraoxonase genotype. Studies on association of the PON 1 gene (Q192R) polymorphism with risk of CAD have been very contradictory $(3,10-11)$. To our knowledge only one report on the association of $192 \mathrm{Q}$ and $\mathrm{R}$ polymorphism in the PON 1 gene with CAD in 
Chinese type 2 diabetics (from the Chinese population in Singapore) exists (11). The purpose of this study, therefore, was to investigate the association of $P O N 1$ gene $192 \mathrm{Gln} / \mathrm{Arg}$ (or Q192R) polymorphism with CAD in 432 Chinese type 2 diabetic patients.

\section{Subjects and methods}

The study spanned from May 1997 through July 1999, and encompassed nine hospitals in the Changzhi region of Shanxi province, China. Informed consent was obtained from all subjects, who were admitted to the hospitals that participated in the study. The study was approved by the institutional review committees of the University of Tsukuba, Ibaraki-ken, Japan and Shanxi Medical University, Shanxi, China.

\section{Selection of patients}

The patient group consisted of 201 randomly selected unrelated type 2 diabetics aged 50-70 years with documented, angiographically confirmed coronary artery disease. The patients were randomly identified from type 2 diabetes patients who underwent cardiac catheterization for symptoms of CAD at the participating hospitals between 1997 and 1999. All patients had previously diagnosed diabetes fulfilling the World Health Organization criteria for type 2 diabetes. The CAD type 2 diabetes cases were matched with non-CAD type 2 diabetic control subjects randomly selected from the same population for sex and age. Angiographic records of five patients were not suitable for analysis, and four male and five female patients were excluded because no age-matched control subjects were available.

\section{Selection of controls}

The control group consisted of 231 type 2 diabetic subjects who showed no ECG or angiographic abnormalities and who met none of the criteria for CAD. For recruitment of controls, we initially randomly selected type 2 diabetes patients aged 50-70 years who showed no angiographic abnormalities and had no documented history of $\mathrm{CAD}$ or other cardiovascular anomalies. Potential control subjects were further screened for electrocardiographic abnormalities, all subjects with suspected cardiovascular abnormalities were excluded. Those subjects selected as controls had no history of angina pectoris (Rose questionnaire), no abnormal Q-wave on ECG (according to the Minnesota code), normal electrocardiograms at rest, and showed no signs of myocardial ischemia in exercise stress testing.

\section{Definition of risk factors}

Coronary angiography was performed by standard techniques with multiple projections and interpreted by two cardiologists who had no prior knowledge of the patient's clinical and laboratory findings. CAD, defined as $>50 \%$ diameter stenosis in any major coronary vessel, was diagnosed by coronary angiography. The extent of stenotic changes was assessed on the basis of the number of stenotic vessels (right coronary, left anterior descending, or left circumflex arteries). Severity of stenosis was determined by a score assigned to each of 15 segments according to the classifications of the American Heart Association grading committee. A normal coronary angiogram was graded $0 ;<25 \%$ stenosis as $1 ; 25-50 \%$ stenosis as $2 ; 50-75 \%$ stenosis as 3 ; and $\geq 75 \%$ stenosis as 4 . A maximum value of 60 derived from the sum total of the above scores was used to define the coronary stenosis index. The CAD patients were then subclassified according to the National Heart, Lung and Blood Institute Coronary Artery Surgery Study (CASS) protocol as having one, two or three major epicardial coronary arteries with $\geq 50 \%$ luminal obstruction (12). Patients who met two of the following criteria were considered to have suffered myocardial infarction: (1) history of prolonged chest pain lasting longer than $30 \mathrm{~min}$ and not responsive to nitroglycerin; (2) elevation of creatinine phosphokinase (CPK), including the CK-MB isoform, of $\geq 6 \%$; (3) pathological Q-waves on ECG during follow-up, and ST segment elevation of $>0.1 \mathrm{mV}$ in at least two leads at the time of diagnosis. Patients exhibiting increased serum activities of enzymes such as creatinine kinase, aspartate aminotransferase, and lactate dehydrogenase were referred. The $201 \mathrm{CAD}$ patients were diagnosed with type 2 diabetes according to the World Health Organization criteria (13). Patients were classed as hypertensive if repeated measurements of systolic blood pressure were $\geq 140 \mathrm{mmHg}$ and diastolic blood pressure $\geq 90 \mathrm{mmHg}$, or if diagnosed with arterial hypertension. Patients were classed as hyperlipidemic when plasma total cholesterol was $>5.2 \mathrm{mmol} / \mathrm{l}$, plasma triglycerides $>1.7 \mathrm{mmol} / \mathrm{l}$ or if using lipidlowering drugs with an established diagnosis of hyperlipidemia. All subjects in both groups lived in the same region (Chanzhi/Shanxi) located in central China. The study population was believed to share the same ethnic ancestry, and a homogeneous genetic background. The distribution of PON 1 gene genotypes and allele frequencies among subjects was within Hardy-Weinberg equilibrium. Clinical and metabolic data were obtained by trained research assistants and nurses using standardized questionnaires and review of medical records and laboratory tests.

\section{Detection of Q192R polymorphism in the human paraoxonase gene}

PCR of the target region in the PON A gene Genomic DNA was extracted from whole blood samples collected in disodium EDTA $(3 \mathrm{mg} / \mathrm{ml})$ according to established 
protocol with slight modification (14). The DNA samples were subjected to amplification by PCR with primers (forward: 5'-TAT TGT TGC TGT GGG ACC TGA G-3'; reverse: 5'-CAC GCT AAA CCC AAA TAC ATC TC-3') that encompass the polymorphic region in the human PON A gene as previously described (6). The amplification reaction was performed in $25 \mu \mathrm{l}$ reaction mixture containing template DNA, forward/ reverse primers, dNTP mixture and Taq DNA polymerase, and reaction buffer obtained from the amplification kit (Takara, Kyoto, Japan). Thermocycling was performed with a Gene Amp PCR system 9066-R (Perkin Elmer, Norwalk, CT, USA) and consisted of an initial denaturation at $94{ }^{\circ} \mathrm{C}$ for $1 \mathrm{~min}$, followed by 40 cycles of denaturation at $94{ }^{\circ} \mathrm{C}$ for $30 \mathrm{~s}$, annealing at $61{ }^{\circ} \mathrm{C}$ for $45 \mathrm{~s}$, and extension at $72{ }^{\circ} \mathrm{C}$ for $45 \mathrm{~s}$, with a final extension time of $5 \mathrm{~min}$. PCR products were applied to SSCP analysis after visualization under UV light in ethidium bromide pre-stained agarose gel.

\section{Single strand confirmational polymorphism (SSCP) analysis}

One microliter of the PCR product was diluted with $14 \mu \mathrm{l}$ loading buffer containing 99.5\% of formamide and $0.5 \%$ Blue Dextran (Pharmacia Biotech, Uppsala, Sweden). After denaturation at $96{ }^{\circ} \mathrm{C}$ for $5 \mathrm{~min}, 2 \mu \mathrm{l}$ of the diluted mixture was applied to $8 \%$ native polyacrylamide gel (49:1 acrylamide: bisacrylamide ratio) in $0.5 \times$ Tris-Borate EDTA buffer (TBE). Electrophoresis was carried out at $400 \mathrm{~V}, 30 \mathrm{~mA}$ and $20 \mathrm{~W}$ for $300 \mathrm{~min}$ at $18{ }^{\circ} \mathrm{C}$. A DNA sequencer (ALFexpress, Pharmacia Biotech) equipped with a short gel plate $(173 \mathrm{~mm} \times 31 \mathrm{~mm} \times 0.5 \mathrm{~mm})$ was used to perform fluorescence-based SSCP analysis. Data were analysed using Fragment Manager software from Pharmacia Biotech.

\section{Sequencing of PCR products}

PCR products from subjects who showed variant wave patterns in SSCP analysis were cut from the 1\% agarose gel after electrophoresis and extracted using Microcon tubes (Amicon, Denver, MA, USA). The purified template DNA was sequenced directly using a genetic analyzer (ABI Prism 310, Perkin Elmer, Norwalk) with the same forward and reverse primers as used for PCR amplification.

\section{Statistical analysis}

Clinical and demographic data were expressed as means \pm S.D. (standard deviation) for continuous variables and as percentages for categorical variables. Comparisons between $\mathrm{CAD}$ diabetics and controls was made using Student's unpaired t-test or the MannWhitney U-test. Allele frequencies in different groups were compared by gene counting and $\chi^{2}$ analysis. Hardy-Weinberg equilibrium was confirmed using the $\chi^{2}$ test. Differences were considered significant when $P<0.05$. Multivariate logistic regression analysis was performed to assess the independent role of the PON 1 genotype, and other $\mathrm{CAD}$ factors, including sex, age, BMI, and history of smoking, hypertension, and hyperlipidemia. All analyses were performed with statistical analysis software (SAS) (16).

\section{Results}

Using SSCP analysis, three different polymorphic patterns were detected in the PON 1 gene from the 201 CAD type 2 diabetic patients and the 231 type 2 diabetic controls. Analysis by PCR direct sequencing of each product revealed three genotypes consisting of two alleles, indicative of base transition from $A$ to $G$ at codon 192. Table 1 shows the distribution of clinical

Table 1 Distribution of clinical and metabolic characteristics between CAD type 2 diabetic patients and type 2 diabetic controls.

\begin{tabular}{|c|c|c|}
\hline Covariates & $\begin{array}{c}\text { CAD type } 2 \text { diabetics } \\
\qquad(n=201)\end{array}$ & $\begin{array}{c}\text { Diabetic controls } \\
\quad(n=231)\end{array}$ \\
\hline Age (years)§ & $63.2 \pm 7.6$ & $63.6 \pm 6.9$ \\
\hline Sex (male/female) & $121 / 80$ & $135 / 96$ \\
\hline Smokers $(\%)^{*}$ & 69.7 & 66.4 \\
\hline Onset age of diabetes (years)§ & $42.6 \pm 8.7$ & $43.9 \pm 5.6$ \\
\hline Diabetes duration (years) & 15.7 & 14.9 \\
\hline BMI $\left(\mathrm{kg} / \mathrm{m}^{2}\right) \S$ & $26.9 \pm 4.2$ & $25.1 \pm 4.5$ \\
\hline Hypertension (\%) & 69.3 & 12.1 \\
\hline Total-C $(\mathrm{mmol} / \mathrm{l})$ & $5.65 \pm 1.09$ & $5.21 \pm 0.95$ \\
\hline $\mathrm{HDL}-\mathrm{C}(\mathrm{mmol} / \mathrm{l}) \S$ & $1.27 \pm 0.23$ & $1.23 \pm 0.34$ \\
\hline LDL-C (mmol/l)†§ & $3.58 \pm 0.15$ & $3.41 \pm 0.21$ \\
\hline LDL/HDL†§ & $2.82 \pm 0.58$ & $2.77 \pm 0.55$ \\
\hline Triglyceride $(\mathrm{mmol} / \mathrm{l}) \dagger \S$ & $1.76 \pm 0.78$ & $1.58 \pm 0.86$ \\
\hline
\end{tabular}

* Includes previous and current smokers

$\dagger P \leq 0.05$.

$\S$ Data are recorded as means \pm standard deviation (S.D.). 
Table 2 Genotype distribution, allele frequencies of paraoxonase 1 gene (Q192R) polymorphism, and odds ratios for CAD in the CAD type 2 diabetic and type 2 diabetic control groups.

\begin{tabular}{|c|c|c|}
\hline Covariates & $\begin{array}{l}\text { CAD type } 2 \\
\text { diabetics } \\
(n=201)\end{array}$ & $\begin{array}{c}\text { Type } 2 \text { diabetic } \\
\text { controls } \\
(n=231)\end{array}$ \\
\hline \multicolumn{3}{|l|}{ PON A genotype } \\
\hline$Q / Q$ & 136 (67.7\%) & $181(78.5 \%)$ \\
\hline$Q / R$ & $43(21.2 \%)$ & $44(19 \%)$ \\
\hline$R / R$ & 22 (10.9\%) & $6(2.5 \%)$ \\
\hline \multicolumn{3}{|l|}{ Allele frequency } \\
\hline$Q$ & $316(78.5 \%)$ & $406(88 \%)$ \\
\hline$R$ & 86 (21.5\%) & $56(12 \%)$ \\
\hline$x^{2}$ & \\
\hline$P$ value & \multirow{2}{*}{\multicolumn{2}{|c|}{$\begin{array}{c}0.0002 \\
1.97(1.36-2.86)\end{array}$}} \\
\hline OR (95\% Cl) & & \\
\hline
\end{tabular}

and metabolic characteristics of the two study groups. There were no significant differences between the groups in terms of age, sex, smoking, BMI and total cholesterol. Genotype distribution and allele frequencies of the PON 1 gene in the CAD diabetes group and the diabetes only group are shown in Table 2 . The $Q$ and $R$ allele frequencies were 78.5 and $21.5 \%$ respectively in the CAD diabetic group and 88.0 and $12.0 \%$, respectively in the diabetes only group. The $R$ allele was significantly associated with the risk of CAD (odds ratio $(\mathrm{OR})=1.97 ; 95 \%$ confidence interval $(\mathrm{CI})=1.36-2.86 ; P=0.0002)$. Table 3 shows genotype distribution, allele frequencies of the PON 1 gene

Table 3 Genotype distribution, allele frequencies of paraoxonase 1 gene (Q192R) polymorphism, and odds ratios for smokers and non-smokers CAD in the CAD type 2 diabetic and type 2 diabetic control groups.

\begin{tabular}{|c|c|c|}
\hline Covariates & $\begin{array}{l}\text { CAD type } 2 \\
\text { diabetics } \\
(n=201)\end{array}$ & $\begin{array}{c}\text { Type } 2 \text { diabetic } \\
\text { controls } \\
(n=231)\end{array}$ \\
\hline $\begin{array}{l}\text { Smoking group } \\
\text { PON A genotype }\end{array}$ & $n=132$ & $n=111$ \\
\hline$Q / Q$ & $86(65 \%)$ & $90(80.7 \%)$ \\
\hline$Q / R$ & $28(21.6 \%)$ & $17(15.2 \%)$ \\
\hline$R / R$ & 18 (13.4\%) & $4(4.1 \%)$ \\
\hline Allele frequency & & \\
\hline$Q$ & 200 (75.8\%) & $196(88.3 \%)$ \\
\hline$R$ & $64(24.2 \%)$ & $26(11.7 \%)$ \\
\hline$x^{2}$ & \multicolumn{2}{|c|}{12.55} \\
\hline$P$ value & \multirow{2}{*}{\multicolumn{2}{|c|}{$\begin{array}{c}0.0004 \\
2.4(1.47-3.9)\end{array}$}} \\
\hline OR $(95 \% \mathrm{Cl})$ & & \\
\hline $\begin{array}{l}\text { Non-smoking group } \\
\text { PON A genotype }\end{array}$ & $n=69$ & $n=120$ \\
\hline$Q / Q$ & $50(72.1 \%)$ & $90(75.3 \%)$ \\
\hline$Q / R$ & $17(24 \%)$ & $25(21 \%)$ \\
\hline$R / R$ & 2 (3.9\%) & $5(3.7 \%)$ \\
\hline \multicolumn{3}{|l|}{ Allele frequency } \\
\hline$Q$ & $116(84.1 \%)$ & 206 (85.8\%) \\
\hline$R$ & $22(15.9 \%)$ & 34 (14.2\%) \\
\hline$x^{2}$ & \multicolumn{2}{|c|}{0.22} \\
\hline$P$ value & \multirow{2}{*}{\multicolumn{2}{|c|}{$\begin{array}{c}0.64 \\
1.15(0.63-1.80)\end{array}$}} \\
\hline OR (95\% Cl) & & \\
\hline
\end{tabular}

Table 4 Multiple logistic regression analysis for the association between CAD and the PON 1 gene 192 genotype, and covariates in $\mathrm{CAD}$ and three-vessel disease. Values presented as odds ratios with $95 \%$ confidence intervals in parentheses.

\begin{tabular}{lll}
\hline Covariates & \multicolumn{1}{c}{ CAD } & $\begin{array}{c}\text { Three-vessel } \\
\text { disease }\end{array}$ \\
\hline Age & $2.45(1.92-6.35)^{\star}$ & $2.98(1.26-7.34)^{\star}$ \\
Sex & $0.87(0.40-1.88)$ & $0.78(0.35-1.75)$ \\
PON 1 R allele & $3.78(1.94-7.40)^{\star}$ & $0.88(0.47-1.66)$ \\
$\quad$ frequency & & \\
Onset age of diabetes & $0.92(0.31-2.75)$ & $2.45(1.84-7.08)^{\star}$ \\
Diabetes duration & $0.85(0.29-2.56)$ & $0.75(0.26-2.17)$ \\
BMI & $1.78(0.69-4.20)$ & $1.97(1.82-4.76)^{\star}$ \\
Hypertension & $3.12(1.60-6.26)^{*}$ & $2.86(1.47-5.72)^{*}$ \\
Hyperlipidemia & $2.97(1.48-6.00)^{*}$ & $2.34(1.23-4.52)^{*}$ \\
History of smoking & $3.21(1.47-7.25)^{*}$ & $2.75(1.32-5.81)^{*}$ \\
\hline
\end{tabular}

${ }^{*} P<0.05$.

and ORs for CAD from the history of smoking in the respective groups. There were significant differences in allele frequencies between the $\mathrm{CAD}$ diabetic group and diabetes only group among smokers $(\mathrm{OR}=2.4 ; 95 \% \mathrm{CI}$ $1.47-3.9 ; P=0.0004)$. However, no significant difference in allele frequencies was observed with regard to CAD diabetic non-smokers and diabetic non-smokers $(\mathrm{OR}=1.15 ; 95 \%$ CI $0.63-1.80 ; P=0.64)$ Results of multiple regression analysis indicated a significant independent association of age, 192R allele, hypertension, hyperlipidemia, and history of smoking with the risk of CAD (Table 4). Furthermore, age, diabetes duration, hypertension, hyperlipidemia and history of smoking were significantly associated with three vessel disease. This observation may imply that the 192R allele is not significant in the three vessel disease, at least in our study population.

\section{Discussion}

The present study further supports the hypothesis that $192 \mathrm{Q}$ and $\mathrm{R}$ polymorphism in the PON 1 gene is associated with CAD in type 2 diabetic patients (10). Studies in Japan confirmed that PON 1 (Q192R) gene polymorphism is related to CAD in Japanese diabetic patients (16). Our results showed that the presence of the 192R allele in the PON 1 gene is associated with the occurrence of CAD in Chinese type 2 diabetic patients. To our knowledge, this is probably the first study to implicate PON 1 gene variants as genetic risk factors for atherosclerotic CAD, and possibly the largest study to determine the PON 1 genotype in Chinese subjects living in central China. Previous reports on the association of PON 1 gene 192 polymorphism with CAD in different populations have been inconsistent with a high prevalence of PON 1 gene 192 polymorphism documented in the Japanese, North American Caucasians and Asian Indians (16-18) whereas studies on Finnish subjects and Chinese Singaporeans found no evidence of an association of the PON 1 
gene 192 Arg allele with $\operatorname{CAD}(3,16-18)$. It is conceivable that gene-environment interaction may play a significant role in the predisposition to CAD.

Until now allelic association studies have been the method of choice for the identification of genetic risk factors of complex traits. The PCR-SSCP technique is now widely used as a screening procedure for detecting mutations in prokaryotes, but is very little used in eukaryotic studies. PCR-SSCP it is easy to perform, less costly, and is a sensitive screening method for the detection of mutations than direct DNA sequencing or restriction fragment length polymorphism (RFLP) analysis. Since the effects of mutations on conformation of single-stranded DNA are more pronounced when the DNA fragments are small, the PCR-SSCP procedure is a good indicator of mutations, especially point mutations, in PCR-amplified regions.

In the present study, we examined 432 type 2 diabetic cases. There were no significant differences between the two groups with respect to clinical and metabolic characteristics; presumably this could be due to the small sample size for cases studied, and the population in question. Multiple logistic regression analyses revealed that association of the Arg allele with CAD in type 2 diabetes was independent of age, smoking history, total serum cholesterol levels and hypertension.

Despite the small sample size, a higher prevalence of the Arg allele was observed in CAD type 2 diabetic patients than in non-CAD type 2 diabetic subjects. It is therefore plausible that the functional role of paraoxonase in type 2 diabetic patients could be profoundly essential. Chronic hyperglycemia causes considerable modification in the structure and function of proteins, mostly due to the non-enzymatic glycation of amino acid residues (19). Additionally, LDL cholesterol containing glycated apolipoprotein-B100 interacts with the vascular endothelium and platelets, leading to increased production of thromboxanes thereby decreasing thrombolytic prostaglandins (20-21). Furthermore, glycated LDL cholesterol is more readily oxidized, resulting in accelerated macrophage uptake by the scavenger receptor pathway (22). The results of the present study and that of the published literature indicate that the protective effects of paraoxonase against peroxidation of LDL particles are important in CAD type 2 diabetes cases. A significant association was also observed between the 192R allele and history of smoking in CAD patients with type 2 diabetes. Smoking, an established risk factor for CAD, has been known to play an important role in the oxidative mechanism. Increased amounts of by-products and free radicals are generated in smokers from lipid peroxidation of oxidized LDL particles than from non-smokers and, as a result, plasma anti-oxidative capacity is lower in smokers than in non-smokers (23-26). Thus, paraoxonase activity could play a protective role in smokers against in vivo peroxidation of lipid. According to recent studies, cigarette smoke extracts have an inhibitory effect on plasma paraoxonase activity (27). In vitro studies have also indicated that the paraoxonase $192 \mathrm{R} / \mathrm{R}$ alloenzyme is less able to protect LDL against the accumulation of lipid peroxides than the alloenzymes containing the $Q$ variant (28-29). The high prevalence of $\mathrm{CAD}$ among diabetic cases could be explained by a multitude of factors: the combined genetically determined lower paraoxonase-mediated protection against lipid peroxidation; the increased non-enzymatic glycation of the resulting oxidative damage caused by hyperglycemia; and the eventual impairment of paraoxonase activity by cigarette smoking may lead to an increased entrapment of oxidized LDL in the arterial wall. The results obtained in this study imply an important role for PON 1 gene (Q192R) polymorphism in the pathogenesis of CAD in Chinese type 2 diabetics. Because of the small sample size in the present study we should be cautious in interpreting and generalizing the results. Further investigations using larger sample sizes in matched case-control studies of various ethnic groups are warranted.

\section{Acknowledgements}

D Osei-Hyiaman and L Hou are supported by the Honjo International Scholarship Foundation, the Asia International Scholarship Foundation, and the Japan Scholarship Foundation, Japan. All authors contributed equally to this study.

\section{References}

1 Hamsten A \& de Faire U. Risk factor for coronary artery disease in families of young men with myocardial infarction. American Journal of Cardiology 198759 14-19.

2 Stamler J, Vaccaro O, Neaton JD, Wentorth D, for the Multiple Risk Factor Intervention Trial Research Group. Diabetes, other risk factors, and 12-yr cardiovascular mortality for men screened in the Multiple Risk Factor Intervention Trial. Diabetes Care 1993 $16434-444$.

3 Antikainen M, Murtomaki S, Syvanne M, Pahlman R, Tahvanainen E, Jauhi-ainen $\mathrm{M}$ et al. The Gln-Arg 191 polymorphism of the human paraoxonase gene (HUMPONA) is not associated with the risk of coronary artery disease in Finns. Journal of Clinical Investigations 199698 883-885.

4 Schwartz CJ, Valente AJ, Sprague EA, Kelley JL, Cayatte AJ \& Rozek MM. Pathogenesis of the atherosclerotic lesion: implication for diabetes mellitus. Circulation 199215 1156-1167.

5 Marenberg MEN, Risch N, Berkman LF, Floderus B \& de Faire U. Genetic susceptibility to death from coronary heart disease in a study of twins. New England Journal of Medicine 1994330 1041-1046.

6 Humbert R, Adler DA, Disteche CM, Hassett C, Omiecinski CJ \& Furlong CE. The molecular basis of the human serum paraoxonase activity polymorphism. Nature Genetics 19933 73-76.

7 Adkin S, Gan KN, Mody M \& La Du BN. Molecular basis for the polymorphic forms of human serum paraoxonase/arylesterase: glutamine or arginine at position 192 for the respective A or B allozymes. American Journal of Human Genetics $1993 \mathbf{5 2}$ 598-608. 
8 Saha N, Roy AC, Teo SH, Tay JSH \& Ratnam SS. Influence of serum paraoxonase polymorphism on serum lipids and apolipoproteins. Clinical Genetics 199140 277-282.

9 Hegele RA, Brunt JH \& Connelly PW. A polymorphism of the paraoxonase gene associated with variation in plasma lipoproteins in a genetic isolate. Arteriosclerosis, Thrombosis, and Vascular Biology 199515 89-95.

10 Ruiz J, Blanche H, James RW, Garin MC, Vaisse C \& Charpentier G. et al. Gln-Arg 192 polymorphism of paraoxonase and coronary heart disease in type 2 diabetes. Lancet 1995346 869-872.

11 Sanghera DK, Saha N, Aston CE \& Kamboh MI. Genetic polymorphism of paraoxonase and the risk of coronary heart disease. Arteriosclerosis, Thrombosis, and Vascular Biology 199717 1067-1073.

12 The National Heart, Lung and Blood Institute Coronary Artery Surgery Study (CASS). The principle investigations of CASS and their associates. Circulation 198163 (Suppl I) 1-81.

13 World Health Organization. WHO Expert Committee on Diabetes Mellitus. Technical Report Series 640. Geneva: World Health Organisation, 1980.

14 Kanai N, Fujii T, Saito K \& Yokoyama T. Rapid and simple method for the preparation of genomic DNA from easily obtainable clotted blood. Journal of Clinical Pathology 1994 47 1043-1044.

15 Cary NC. Users Guide: Procedures, version 6, edn 4, pp 3-44, North Carolina: SAS Institute Inc, 1990.

16 Zama T, Murata M, Matsubara Y, Kawano K, Aoki N, Yoshina H et al. A ${ }^{192} \mathrm{Arg}$ variant of the human paraoxonase (HUMPONA) gene polymorphism is associated with an increased risk for coronary artery disease in Japanese. Arteriosclerosis, Thrombosis, and Vascular Biology 199717 3565-3569.

17 Serrato M \& Marian AJ. A variant of human paraoxonase/ arylesterase (HUMPONA) gene is a risk factor for coronary artery disease. Journal of Clinical Investigation 199596 3005-3008.

18 Suehiro T, Nakauchi Y, Yamanoto M, Arii K, Itoh H, Hamashige N et al. Paraoxonase gene polymorphism in Japanese subjects with coronary heart disease. International Journal of Cardiology 1996 $5769-73$.

19 Schwartz CJ, Valente AJ, Sprague EA, Kelley JL, Cayatte AJ \& Rozek MM. Pathogenesis of the atherosclerotic lesion: implications for diabetes mellitus. Circulation 199215 1156-1167.

20 Lyons TJ, Li W, Wells-Knecht MC \& Jokl R. Toxicity of mildly modified low density lipoproteins to cultured retinal capillary endothelial cell and pericytes. Diabetes $1994 \mathbf{4 3}$ 1090-1095.

21 Watanabe J, Wohltmann HJ, Klein RL, Colwell JA \& LopesVirella MF. Enhancement of platelet aggregation by low-density lipoproteins from IDDM patients. Diabetes 199837 1652-1657.
22 Kobayashi K, Watanabe J, Umeda F \& Nawata H. Glycation accelerates the oxidation of low density lipoprotein by copper ions. Endocrine Journal 199542 461-465.

23 Church DF \& Pryor WA. The free radical chemistry of cigarette smoke and its toxicological implications. Environmental Health Perspectives $198564111-126$.

24 Chow CK, Thacker RR, Changcit C, Bridges RB, Rehm SR, Humble J et al. Lower levels of vitamin $\mathrm{C}$ and carotenes in plasma of cigarette smokers. Journal of the American College of Nutrition $19865305-312$.

25 Princen HMG, Van Poppel G, Vogelezang C, Buytenhek R \& Kok FJ. Supplementation with vitamin E but not $\beta$-carotene in vivo protects low density lipoprotein from lipid peroxidation in vitro. Effect of cigarette smoking. Arteriosclerosis and Thrombosis $199212554-562$.

26 Scheffler E, Wiest E, Woehrle J, Otto I, Schulz I, Huber L et al. Smoking influences the atherogenic potential of low-density lipoprotein. Clinical and Investigative Medicine $1992 \quad \mathbf{7 0}$ 263-268.

27 Nishio E \& Watanabe Y. Cigarette smoke extract inhibits plasma paraoxonase activity by modification of the enzyme's free thiols. Biochemical and Biophysical Research Communications 1997236 289-293.

28 Mackness MI, Arrol S, Mackness B \& Durrington PN. Alloenzymes of paraoxonase and effectiveness of high-density lipoproteins in protecting low-density lipoprotein against lipid peroxidation. Lancet 1997349 851-852.

29 Mackness B, Mackness MI, Arrol S, Turkie W \& Durrington PN. Effect of the human serum paraoxonase 55 and 192 genetic polymorphisms on the protection by high density lipoprotein against low density lipoprotein oxidative modification. FEBS Letters $1998 \mathbf{4 2 3}$ 57-60.

30 Herrmann SM, Blanc H, Poirier O, Arveriler D, Luc G, Evans A et al. The Gln/Arg polymorphism of human paraoxonase (PON192) is not related to myocardial infarction in the ECTIM Study. Atherosclerosis $1996 \mathbf{1 2 6} 299-303$.

31 Falk E, Shah PK \& Fuster V. Coronary plaque disruption. Circulation 199592 657-671.

Received 31 July 2000

Accepted 25 January 2001 